\title{
Tolerância ao frio do amendoim forrageiro
}

\author{
Cold tolerance of forage peanut
}

\author{
Adriana Pires Soares Bresolin ${ }^{\mathrm{I}}$ Caroline Marques Castro ${ }^{\mathrm{II}}$ Flavio Gilberto Herter $^{\mathrm{II}}$ \\ Antonio Costa de Oliveira ${ }^{\mathrm{III}}$ Fernando Irajá Felix de Carvalho ${ }^{\mathrm{III}}$ Felipe Bermudez Pereira ${ }^{\mathrm{IV}}$ \\ Charles Lopes Vieira ${ }^{\mathrm{IV}}$ Rudnei Ferreira Bertoli ${ }^{\mathrm{V}}$
}

\section{- NOTA -}

RESUMO

A produtividade de uma pastagem perene tropical, em regiões de clima temperado, é dependente de seu comportamento em relação às condições de temperatura. A avaliação da sensibilidade das plantas, através da sua exposição a temperaturas inferiores $a 2^{\circ} \mathrm{C}$ em ambiente controlado, pode ser um procedimento bastante eficiente na predição de resistência, em função de assegurar uma homogeneidade dos níveis de frio. Considerando-se à reduzida disponibilidade de trabalhos científicos relacionados com a avaliação de leguminosas forrageiras tropicais quanto à tolerância ao frio, este experimento teve como objetivo avaliar o comportamento do amendoim forrageiro (cv. "Amarillo") sob temperaturas inferiores a $2^{\circ} \mathrm{C}$. O delineamento experimental adotado foi completamente casualizado com 15 repetições e dois tratamentos, com exposição (CE) e sem exposição ao frio (SE). Os caracteres mensurados foram: número de folhas por estolho, espessura do estolho e número de brotações novas. Os resultados indicaram que a exposição do amendoim forrageiro a um intervalo de temperatura de $-1,0$ a $1,3^{\circ} \mathrm{C}$ por um período de 3 horas é capaz de causar estresse de frio nas plantas, provocando uma redução no número de folhas e estimulando a formação de novas brotações, sem provocar a morte das plantas.

Palavras-chave: Arachis pintoi, forrageira tropical, tolerância ao frio.

\begin{abstract}
The yield of tropical perennial forages in temperate climate areas depends on its cold tolerance. The exposure of genotypes to temperatures below $2^{\circ} \mathrm{C}$, under controlled conditions is an efficient methodology to predict cold tolerance, since it maintains homogeneous levels of cold. Due to absence of information related to cold tolerance of tropical forages, this experiment was developed aiming to evaluate the behavior of forage peanut exposed to temperatures below $2^{\circ} \mathrm{C}$. The design adopted was completely randomized with 15 replications and two treatments: exposed and not exposed to cold. The traits measured were: number of leaves per stolon; thickness of stolon and number of new shoots. The results showed that the exposition of the forage peanut to a range of temperature from -1.0 to 1.3 ${ }^{\circ} \mathrm{C}$, for 3 hours, causes cold stress in the plants, resulting in a reduction of the number of leaves per solon and stimulating the emergency of new shoots, but did not kill the plants.
\end{abstract}

Key words: Arachis pintoi, tropical forage, cold tolerance.

O amendoim forrageiro, Arachis pintoi, é uma leguminosa herbácea, perene, com hábito de crescimento prostrado e estolonífero, endêmica da flora brasileira (KRAPOVICKAS \& GREGORY, 1994). Possui valor nutritivo superior à maioria das leguminosas tropicais comerciais (LADEIRA et al., 2002).

'Programa de Pós-graduação em Agronomia, Departamento de Fitotecnia, Faculdade de Agronomia Eliseu Maciel (FAEM), Universidade Federal de Pelotas (UFPel), Campos Universitário, s/n, CP 354, 96010-900, Capão do Leão, RS, Brasil.

"Embrapa Clima Temperado, Pelotas, RS, CP 403, 96001-970. E-mail: caroline@cpact.embrapa.br. *Autor para correspondência. IIIFAEM/UFPel, Capão do Leão, RS, Brasil.

${ }^{\text {IV } C u r s o ~ d e ~ A g r o n o m i a, ~ F A E M / U F P e l, ~ C a p a ̃ o ~ d o ~ L e a ̃ o, ~ R S, ~ B r a s i l . ~}$

vPrograma de estágio Embrapa Clima Temperado, Pelotas, RS, Brasil. 
A Região Sul tem grande expressão econômica na agropecuária brasileira. A inclusão de leguminosas em pastagens proporciona um aumento da produtividade animal, devido ao incremento nos níveis de proteína, de digestibilidade e do consumo da forragem disponível (PETRITZ et al., 1980; BLASER, 1982). Diante do grande potencial de produção e qualidade do amendoim forrageiro, estudos relacionados à avaliação de genótipos quanto à capacidade de adaptação às condições edafoclimáticas do Sul do Brasil são de suma importância, de forma a assegurar a expansão do cultivo desta espécie na região.

Do ponto de vista climático, a geada é o mais importante fator de risco para as culturas na Região Sul do Brasil, onde ocorre grande variabilidade climática, fato comum a regiões de latitude média a alta (CUNHA, 2003). Pode-se considerar a ocorrência de geada quando a temperatura mínima registrada em abrigo meteorológico for inferior ou igual a $2^{\circ} \mathrm{C}$, o que corresponde a aproximadamente $0^{\circ} \mathrm{C}$ na relva (GRODZKI et al., 1996).

Na Região Sul do Brasil, mais precisamente no município de Pelotas, a probabilidade de temperatura mínima inferior a $2^{\circ} \mathrm{C}$ é de 30 a $50 \%$ no mês de julho (WREGE et al., 2004).

A avaliação da sensibilidade das plantas através da sua exposição à temperaturas inferiores a $2^{\circ} \mathrm{C}$, em ambiente controlado, pode ser um procedimento bastante eficiente na predição de resistência em função de assegurar uma homogeneidade dos níveis de frio. Em trevo branco, a seleção de genótipos tolerantes nos experimentos em ambientes controlados é bastante eficiente (ANNICCHIARICO et al., 2001).

Devido à reduzida disponibilidade de trabalhos científicos relacionados com a avaliação de leguminosas forrageiras tropicais quanto à tolerância ao frio, este experimento teve como objetivo testar o comportamento do amendoim forrageiro sob condições de temperaturas entre -1 e $1,3^{\circ} \mathrm{C}$.

O genótipo utilizado no experimento foi a cultivar "Amarillo” em função da sua tolerância ao frio, evidenciada em avaliações preliminares a campo, onde se mostrou vigorosa e produtiva nos primeiros anos de avaliação, apresentando precoce recuperação da parte aérea, maior vigor de rebrote após a estação fria e um período produtivo mais longo, devido, possivelmente, a uma interação entre o potencial genético das plantas e as condições climáticas do Sul do Brasil (DAMÉ et al., 1998).

Em dezembro de 2005, sementes da cultivar “Amarillo” foram semeadas em bandejas de isopor com solo estéril. Após a germinação, as plântulas foram transplantadas individualmente para sacos plásticos de um litro com solo estéril adubado conforme recomendação da CQFS-RS/SC (2004). Em janeiro de 2006, foram selecionadas 30 plantas para compor o experimento. O critério adotado na seleção das plantas foi a uniformidade de tamanho e número de ramificações. De cada planta que compôs o experimento, foram marcados 10 estolhos aleatoriamente. O delineamento adotado foi completamente casualizado com 15 repetições e dois tratamentos, com exposição (CE) e sem exposição ao frio (SE).

As plantas foram expostas a uma temperatura média de $0,4^{\circ} \mathrm{C}$ por três horas, com mínima de $-1^{\circ} \mathrm{C}$ e máxima de $1,3^{\circ} \mathrm{C}$. Em $16 / 01 / 2006$, foram transferidas do telado para a câmara de crescimento, sendo a temperatura ambiente do interior do equipamento constantemente registrada por meio de um termógrafo eletrônico, marca ESPEC, modelo RT 11. As plantas que foram submetidas ao estresse passaram por um período de aclimatação na câmara de crescimento, partindo de uma temperatura inicial de $26,1^{\circ} \mathrm{C}$, registrada no dia $16 / 01 / 2006$, sendo gradativamente reduzida, no período de 48 horas, alcançando $1,1^{\circ} \mathrm{C}$ às $8: 30 \mathrm{~h}$ do dia $18 / 01 / 2006,-1^{\circ} \mathrm{C}$ às 9:30h, $0,1^{\circ} \mathrm{C}$ às $10: 30 \mathrm{~h} \mathrm{e} 1,3^{\circ} \mathrm{C}$ às $11: 30 \mathrm{~h}$ do mesmo dia, totalizando $3 \mathrm{~h}$ de exposição a temperaturas inferiores a $2^{\circ} \mathrm{C}$. Posteriormente ao tratamento, a temperatura foi sendo gradativamente elevada por um período de 48 horas, registrando $28,8^{\circ} \mathrm{C}$ no último dia na câmara de crescimento, 20/01/2006, para posterior exposição à temperatura ambiente. Concomitantemente ao registro das temperaturas na câmara, foram computadas as variações de temperatura no telado onde permaneceram as plantas sem exposição ao frio, dos dia 16/01/2006 a 20/01/2006. A temperatura média registrada no telado foi de $23^{\circ} \mathrm{C}$, com máxima de $30,6^{\circ} \mathrm{C}$ e mínima de $13,8^{\circ} \mathrm{C}$.

Os parâmetros mensurados foram: número de folhas por estolho; espessura do estolho (mm), mensurada com o auxílio de um paquímetro digital, na porção mediana entre o primeiro e o segundo nó, no sentido base/ápice do ramo e número de brotações novas. Com exceção do número de brotações novas, que foi mensurado apenas aos sete dias após o tratamento, os demais caracteres foram avaliados durante um período de 60 dias, totalizando sete avaliações.

Os dados obtidos foram analisados através do programa estatístico SAS (SAS Inst. Inc., 2001). Para os parâmetros que evidenciaram significância na análise de variância, as médias dos tratamentos foram comparadas pelo teste de Tukey a $5 \%$.

A análise conjunta das avaliações evidenciou interação significativa entre tratamento $\mathrm{x}$ 
avaliação para o parâmetro número de folhas/estolho. Dessa forma, foi realizada uma análise individual considerando cada período de avaliação. Por outro lado, para o parâmetro espessura do estolho, a interação tratamento $\mathrm{x}$ avaliação não foi significativa, procedendose, portanto, a uma análise conjunta dos períodos de avaliação. As diferenças apresentadas pela análise de variância foram significativas entre os tratamentos com exposição (CE) e sem exposição ao frio (SE) para os parâmetros avaliados, número de folhas/estolho e número de brotações novas. Durante todo o período de avaliação, num total de sessenta dias, as plantas submetidas ao tratamento com frio apresentaram um número inferior de folhas, quando comparadas com as plantas que não foram submetidas ao tratamento, devido à morte de folhas em decorrência do estresse de frio. Por outro lado, foi evidenciado que o tratamento levou a um significativo aumento no número de brotações novas. As plantas que foram submetidas ao estresse apresentaram em média 29,60 novas brotações por planta, enquanto que as plantas não submetidas ao estresse apresentaram em média 10,86 brotações novas por planta. Esses resultados concordam com BEINHART (1963), que verificou que baixas temperaturas causavam uma drástica redução no número de folhas em plantas de trevo branco, enquanto que o número de ramificações novas era aumentado.

A resposta morfológica diferenciada de folhas e ramos em relação às variações de temperatura resulta em uma maior relação de ramos por área do que de folhas, quando as plantas são expostas ao frio (BOLLER \& NÖSBERGER, 1983). O mecanismo de controle envolvido nesta resposta, embora ainda pouco esclarecido, está relacionado com a genética e fisiologia das plantas. Segundo AUDUS (1972), os processos fisiológicos estão associados a mudanças nos níveis de hormônios tanto dos promotores quanto dos inibidores de crescimento, e estes são diretamente influenciados pelas variações de temperatura. Em fruteiras perenes de clima temperado, cada cultivar reage diferentemente frente às variações climáticas (CAMELATTO, 1990).

A exposição ao frio não resultou em aumento no diâmetro do estolho das plantas avaliadas, diferindo dos resultados encontrados em trevo branco por BOLLER \& NÖSBERGER (1983), em que as plantas submetidas a um regime de baixa temperatura apresentaram em média 33\% de aumento no diâmetro dos estolões. Segundo BOLLER \& NÖSBERGER(1983), em trevo branco, leguminosa de estação fria, a reserva de carboidratos é favorecida pela exposição da planta a baixas temperaturas, permitindo que este aumento na quantidade de reservas seja mensurado através do incremento no diâmetro dos estolões. Em amendoim forrageiro, leguminosa de clima tropical, não foi evidenciado incremento no diâmetro do estolho.

A exposição do amendoim forrageiro, cv. “Amarillo”, a um intervalo de temperatura de -1 a $1,3^{\circ} \mathrm{C}$ por um período de 3 horas é capaz de causar estresse de frio nas plantas, provocando uma redução no número de folhas (NF) e estimulando a formação de novas brotações (NBN), sem provocar a morte das plantas, viabilizando, portanto, a utilização destes caracteres (NF e NBN) como ferramenta de seleção indireta de plantas tolerantes ao frio.

\section{AGRADECIMENTOS}

Os autores agradecem à Fundação de Amparo à Pesquisa do Estado do Rio Grande do Sul (FAPERGS), à Coordenação de Aperfeiçoamento de Pessoal de Nível Superior (CAPES) e ao Conselho Nacional de Desenvolvimento Científico e Tecnológico (CNPq), pelos auxílios recebidos e concessões de bolsas de iniciação científica, pós-graduação e produtividade em pesquisa.

\section{REFERÊNCIAS}

ANNICCHIARICO, P. et al. Variation in cold tolerance and spring growth among Italian white clover populations. Euphytica, v.122, p.407-416, 2001.

AUDUS, L.J. Natural plant growth inhibitors. In: AUDUS, L.J. Plant growth substances. 3.ed. London: Leonard Hill Books, 1972. p.155-177.

BEINHART, G. Effects of environment on meristematic development, leaf area, and growth of white clover. Crop Science, v.3, p.209-213, 1963.

BOLLER, B.C.; NÖSBERGER, J. Effects of temperature and photoperiod on stolon characteristics, dry matter partitioning, and nonstructuiral carbohydrate concentration of two white clover ecotypes. Crop Science, v.23, p.1057-1062, 1983.

BLASER, R.E. Integrated pasture and animal management. Tropical Grasslands, v.16, n.1, p.9-24, 1982.

CAMELATTO, D. Dormência em fruteiras de clima temperado. Horti Sul, v.1, n.3, p.12-17, 1990.

COMISSÃO DE QUÍMICA E FERTILIDADE DO SOLO - RS/ SC. Manual de adubação e calagem para os Estados do Rio Grande do Sul e de Santa Catarina. 10.ed. Porto Alegre: SBCS - Núcleo Regional Sul/UFRGS, 2004. 400p.

CUNHA, G.R. Meteorologia: fatos e mitos. Passo Fundo: Embrapa Trigo, 2003. 440p.

DAMÉ, P.R.V.et al. Produção e qualidade de forragem de acessos de Arachis pintoi em condições de clima temperado no Litoral Sul do Rio Grande do Sul. Agropecuária de Clima Temperado, v.1, p.235-243, 1998.

Ciência Rural, v.38, n.4, jul, 2008. 
GRODZKI, L. et al. Risco de ocorrência de geada no Estado do Paraná. Revista Brasileira de Agrometeorologia, v.4, n.1, p.93-99, 1996.

KRAPOVICKAS, A.; GREGORY, W.C. Taxonomia del género Arachis (Leguminosae). Bonplandia, v.8, n.1-4, p.1-186, 1994.

LADEIRA, M.M. et al. Avaliação de feno de Arachis pintoi utilizando o ensaio de digestibilidade in vivo. Revista Brasileira de Zootecnia, v.31, p.2350-2356, 2002.
PETRITZ, D.C. et al. Performance and economic return of beef cows and calves grazing grass-legume herbage. Agronomy Journal, v.72, n.4. p.581-584, 1980.

SAS INSTITUTE. Getting started with the SAS. Learning edition. Carry, North Caroline, 2001. 131p.

WREGE, M.S. et al. Zoneamento agroclimático para a cultura do citros no Rio Grande do Sul. Pelotas: Embrapa Clima Temperado, 2004. 21p. (Documentos, n.117). 